\title{
Erratum
}

\section{Biotope use and trends of European butterflies}

Chris van Swaay ${ }^{1,4, *}$, Martin Warren $^{2,4}$ and Grégoire Loïs ${ }^{3}$

${ }^{1}$ Dutch Butterfly Conservation, P.O. Box 506, NL-6700, AM Wageningen, The Netherlands; ${ }^{2}$ Butterfly Conservation Manor Yard, East Lulworth, Wareham, Dorset, BH20 5QP, United Kingdom; ${ }^{3}$ European Topic Centre on Biological Diversity, Muséum National d'Histoire Naturelle, 57, Rue Cuvier, 75231, Paris cedex 05, France; ${ }^{4}$ Butterfly Conservation Europe (BCE), P. O. Box 506, NL-6700, AM Wageningen; *Author for correspondence (e-mail: chris.vanswaay@vlinderstichting.nl; phone: +31-317-467342; fax: +31-317-420296)

Published in Journal of Insect Conservation, Volume 10, No. 2, pp. 189-209 (2006).

DOI 10.1007/s10841-006-6293-4

Due to a technical problem during the production process, an unfortunate error occurred within Appendix 1 of the above mentioned article. Regretfully, page 202 has been duplicated causing the data from page 201 to be missing in its entirety. On the following page, the correct reproduction has been published which should be treated as definitive by the reader. 


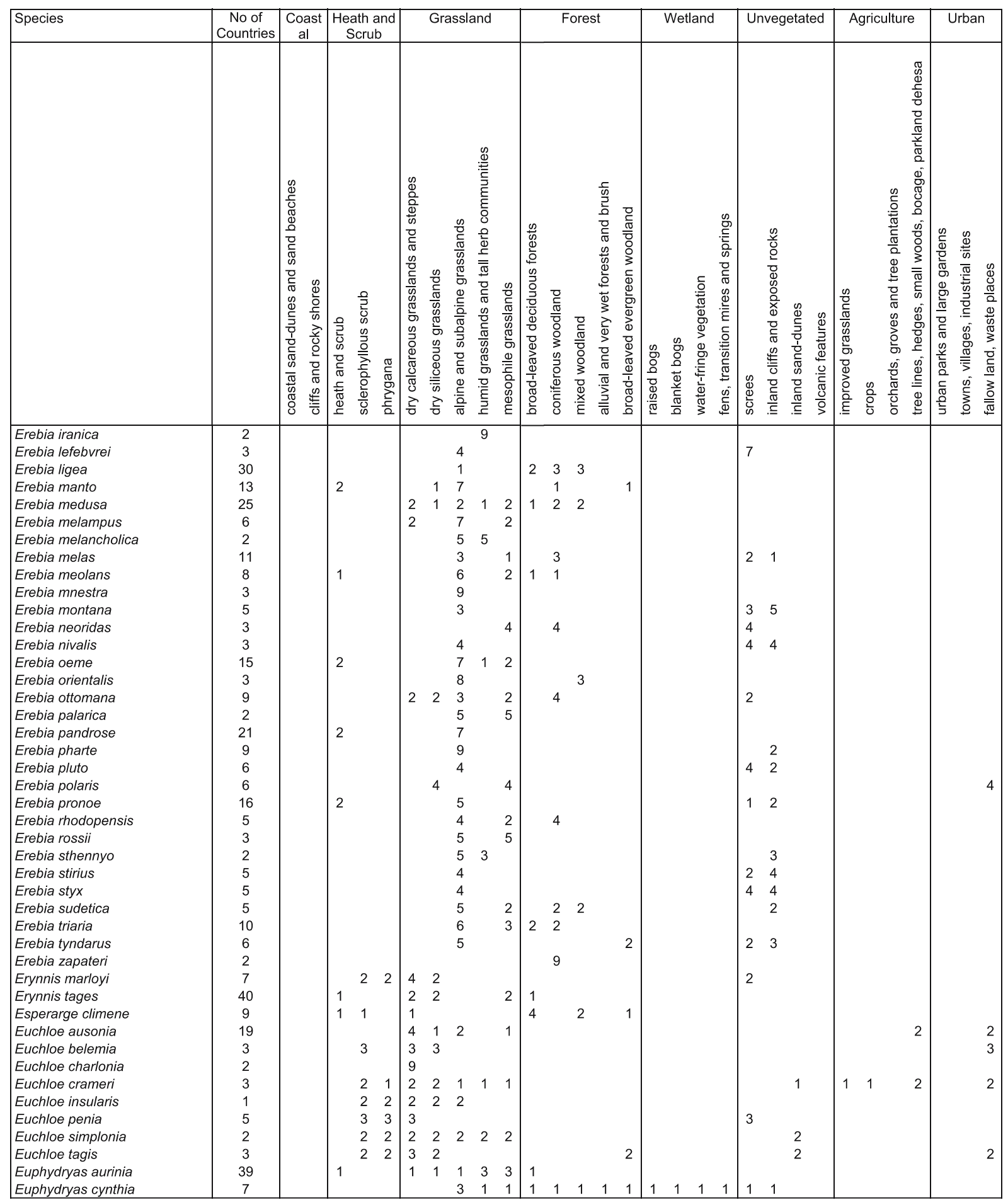

